\title{
IMPORTANCE OF PEROPERATIVE CLOSURE OF ABDOMEN WITH INLAY PROLENE MESH IN POST TRANSVESICAL PROSTATECTOMY IN PATIENTS OF LARGE BPH WITH COPD
}

\author{
Kodandarao $K^{1}$, Rameshbabu $B^{2}$
}

${ }_{1}^{1}$ Assistant Professor, Department of General Surgery, GIMSR, Visakhapatnam, Andhra Pradesh, India.

${ }^{2}$ Assistant Professor, Department of Pulmonary Medicine, GIMSR, Visakhapatnam, Andhra Pradesh, India.

\begin{abstract}
BACKGROUND
ABSTRACT

Those with comorbid conditions like COPD, diabetes, HTN etc. are selected apart from the consideration of advanced age and BPH. Lot of clinical work has to be done for the study. In the light of conventional surgery, the new approach is designed for better results. While most of the elderly patients of 65 - 70 years present with symptoms of $\mathrm{BPH}$, those with urinary retention are selected for surgery after screening.

Aim- To know the importance and efficacy of large inlay mesh, while closing the abdomen after transvesical prostatectomy to prevent second major surgery in elderly BPH patients operated for large prostate.
\end{abstract}

\section{MATERIALS AND METHODS}

It is a prospective observational study. The total number of cases was 53 . They were divided into 2 groups, $\mathrm{X}$ and $\mathrm{Y}$. $\mathrm{X}$ group contains 23 cases and Y group contains 30 cases and conclusions were drawn. Statistical analysis was done by using Tukey's test and Chi-square test using SPSS software 22.0 version. The study was done over a period of 3 years from 2015 to 2018 . Cases are of highly selective nature, involved to fulfil the criteria of advanced age, large size of Benign Prostatic Hypertrophy (BPH), Chronic Obstructive Pulmonary Disease (COPD), Diabetes and Hypertension. The method of surgery chosen was open-operative procedure and not endoscopic type like TURP. Among the open operative type procedures, the comparison is made between mesh and without mesh closure of the abdomen in one sitting during the course of transvesical prostatectomy total procedure. The sample size was taken for convenience during the study.

\section{RESULTS}

Of the many cases of BPH, 53 patients of large BPH with urinary retention of age between 65 and 75 years with Chronic Obstructive Pulmonary Disease (COPD) and diabetes are selected for the current study. Twenty-three cases without mesh closure and 30 patients with mesh of abdominal closure are compared and conclusions drawn.

\section{CONCLUSION}

Routine peroperative closure of abdomen in infraumbilical laparotomy for transvesical prostatectomy in elderly patients with COPD and diabetes obviates the need for second major surgery and reduces morbidity, enhances recovery and minimi ses hospital stay. These concluding remarks are very valuable in planning open abdominal surgery in patients with COPD and diabetes. In the absence of COPD, there can be occasional chances of lack of wound dehiscence in certain individuals, though with hypertension but not with diabetes. But in this study, COPD is the main criterion to choose cases for this comparative study with a novel procedure.

\section{KEY WORDS}

Elderly Male, BPH, Prostatectomy, COPD, Inlay Mesh.

HOW TO CITE THIS ARTICLE: Kodandarao K, Rameshbabu B. Importance of peroperative closure of abdomen with inlay prolene mesh in post transvesical prostatectomy in patients of large BPH with COPD. J. Evolution Med. Dent. Sci. 2018;7(36):3964-3967, DOI: $10.14260 /$ jemds/2018/886

\section{BACKGROUND}

Prostate is a fibromuscular stroma[1] of size about $3 \mathrm{~cm} \times 3.5$ $\mathrm{cm}$. Benign prostatic hypertrophy starts in the periurethral transitional zone and compresses the peripheral zone, which becomes the false capsule and there is also the outer true fibrous anatomical capsule. Largeness of the size of prostate is measured by size in cms and also by the direction of enlargement of lobes obstructing the urethra.

'Financial or Other Competing Interest': None.

Submission 13-06-2018, Peer Review 18-08-2018,

Acceptance 24-08-2018, Published 03-09-2018.

Corresponding Author:

Dr. Rameshbabu B,

Sri Krishna Enclave,

Flat No. 301, Yendada

Visakhapatnam, Andhra Pradesh, India.

E-mail: saradarameshbabu1960@gmail.com

DOI: $10.14260 /$ jemds $/ 2018 / 886$

\section{(c) (i) $(5)$}

Thorough evaluation of the patients is very very essential for good prospective outcome. Extra care is taken in the very selection of patients for this novel procedure, keeping in view the welfare of them.

Extraperitoneal Transvesical Prostatectomy is the gold standard of treatment for large BPH in elderly patients with COPD. ${ }^{[2]}$ Due to the presence of co-morbid conditions like diabetes, hypertension, age-related atherosclerosis in these patients and post-operative complications often distressing are anticipated and they cannot sustain for long with these aliments. So, a suitable preventive procedure has to be thought of by the surgeon even before planning the actual definitive procedure. Often post-operatively wound dehiscence, wound infection, late complication of divarication of recti abdomen are reported due to increased intrathoracic and intra-abdominal pressure and compromised state, especially in diabetic conditions. [3] The abdomen may remain open even with or without intact peritoneum and it may not heal even for months or weeks due to constant raised intra- 
abdominal pressure. Secondary closure of the abdomen is another major surgical procedure done within less than three months post-operatively is a great burden on an aged individual, which may even require ventilatory support in an ICU setup. In such cases peroperative closure ${ }^{[4]}$ with large preperitoneal prolene mesh can minimise morbidity and the chances of secondary closure of the abdomen with tension sutures and also prolonged hospital stay is minimised to a great extent.

\section{MATERIALS AND METHODS}

It is a prospective observational study. The total number of 53 cases are divided into 2 groups $X$ and $Y$. X group contains 23 cases and Y group contains 30 cases and conclusions drawn. The study was performed over the period of three years from 2015 - 2018. The sample size was taken for convenience during the study.

The method of surgery chosen was open-operative procedure and not endoscopic type like TURP. Among the open-operative type procedures, the comparison is made between mesh and without mesh closure of the abdomen in one sitting during the course of transvesical prostatectomy total procedure.

\section{Study Design}

All the cases were done in outside clinical practice. The surgery performed by general surgeon worked in the wards of urology. Only the paper work and discussions are made at the research centre, GITAM Institute of Medical Sciences and Research, where the main author and corresponding author are working at present for the past one year.

Of the many cases of BPH, 53 patients of large BPH with urinary retention of age between 65 and 75 years with Chronic Obstructive Pulmonary Disease (COPD) and diabetes and HTN were selected for the comparative study. Twentythree cases without mesh closure and 30 patients with mesh of abdominal closure were compared and conclusions drawn.

All elderly cases with urinary retention were screened for $\mathrm{BPH}$. All patients were thoroughly evaluated. After routine blood tests, ECG and screening, midstream urine culture, specific tests for BPH, COPD and diabetes were performed. Per rectal examination of the prostate was done for the clinical diagnosis of BPH. Ultrasound (USG) per abdomen and transrectal probe study was performed to note the details of the prostate and its relation to surrounding structures like urethra, bladder and rectum. Prostate Specific Antigen (PSA) test was done for all cases to exclude carcinoma prostate, the value is $<2.5 \mathrm{nmol} / \mathrm{L}$. Diabetes was evaluated with routine blood sample study of fasting, PP blood glucose levels and $\mathrm{HbA}_{1} \mathrm{C}$. The value of $\mathrm{HbA}_{1} \mathrm{C}$ below 7 is chosen for surgery. Urodynamic study for BPH was performed. Peak flow rate $<10 \mathrm{~mL} / \mathrm{sec}$ and voiding volume $>200 \mathrm{~mL}$ were selected for the surgery and the study. Evaluation for COPD was performed with lung function tests like PEFR, PFT, FEV $1, A B G$ and digital $\mathrm{x}$-ray chest in different views. COPD patients are treated effectively by the pulmonologist with inhalational drugs like Tiotropium Br 18 mcg OD, Budecort 200 mcg SOS and Salbutamol. $\mathrm{SPO}_{2}$ is maintained at $98 \%$. Condition is improved and brought to normalcy. Pre-anaesthetic check-up is performed for the fitness for surgery. HTN was treated with ARBs, $\beta$-blockers are avoided. Cystourethroscopy was performed preoperatively. Surgery was done under epidural anaesthesia. ${ }^{[5,6,7]}$
Informed consent was taken in all cases for surgery. Counselling was done. The antecedent problems associated with the surgery in a morbid patient are explained in detail to the patients and to their relatives in vernacular and their signatures, co-relation to each other and their contact numbers with addresses are taken in the informed consent form. To allay the fears of the patients and their relatives and about the financial burden, series of counselling sessions are conducted at regular intervals and finally the operative procedures were conducted confidently with their support. No problems were experienced, either with the patients or with their relatives at any time during the course of surgery or post-operatively.

\section{Statistical Analysis}

Chi-square test and independent t-test are used in statistical methodology. The methods of surgical procedures are mentioned in the document with SPSS software 22.0 version.

\section{RESULTS}

In about 23 cases of large BPH with COPD, extraperitoneal transvesical prostatectomy was done and 19 out of 23 patients reported post-operative wound dehiscence and 5 patients with divarication of recti abdomen (Table-1).[8] Urine with serosanguinous discharge from the infraumbilical wound and excoriation on the skin over the abdomen with poor wound healing with late recovery were the problems encountered in the post-operative period.[9] So, the need for preoperative closure with preperitoneal inlay prolene mesh arose, which was done in another 30 patients. The operating time for peroperative mesh closure is more, but not so much prolonged (Figure-1). Minor problems like mild cough, lowgrade fever, nutrition and anaemia were managed. Chest physiotherapy and psychological support prevailed throughout the course of management. Postoperatively, again 18 cases reported with wound dehiscence, but with protected undercover of prolene mesh. The duration of hospital stay is significantly reduced in peroperative mesh closures (Table2). Retrograde ejaculation was reported, but transient.[10] No other complications like excess bleeding or sepsis, atelectasis, DVT, water intoxication or erectile impotence are reported. Wound infection was there, but not as much as in cases of anatomical closure and treated with good antibiotic cover.

\begin{tabular}{|c|c|c|c|}
\hline 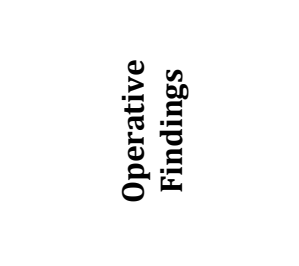 & 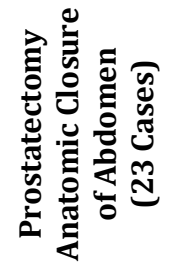 & 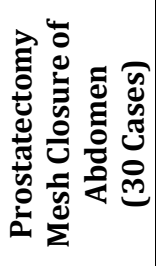 & 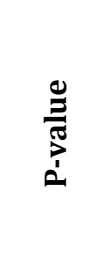 \\
\hline $\begin{array}{l}\text { Operating time } \\
\text { (in mm) }\end{array}$ & $75(11.45)$ & $\begin{array}{c}120 \\
(14.89)\end{array}$ & $<0.01$ \\
\hline \multicolumn{4}{|c|}{ Post-Operative Complications } \\
\hline Wound dehiscence & 19 & 18 & $0.07 \mathrm{NS}$ \\
\hline Wound infection & 11 & 9 & $0.18 \mathrm{NS}$ \\
\hline $\begin{array}{c}\text { Late complication } \\
\text { (Divarication of recti) }\end{array}$ & 5 & 2 & $0.10 \mathrm{NS}$ \\
\hline To 1 C & $\begin{array}{l}\text { Complica } \\
\text { Surgery }\end{array}$ & & $\bar{f}$ \\
\hline
\end{tabular}

*P-value: Probability value, NS: Non-significant. 


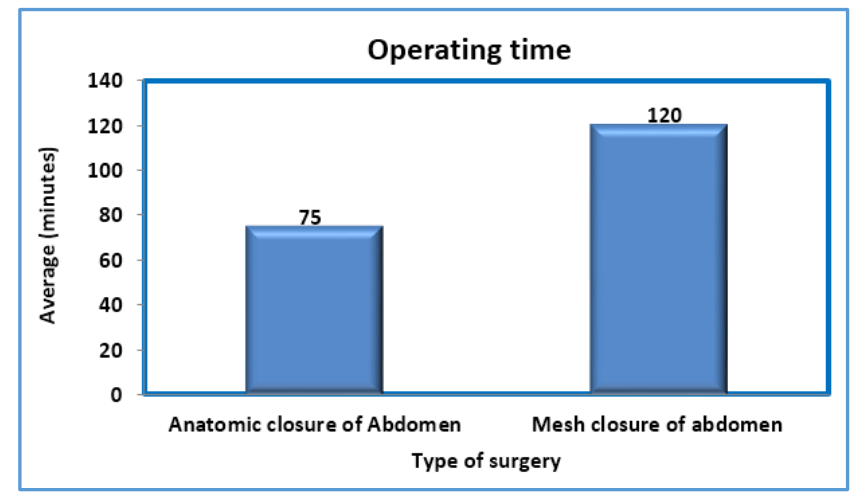

Figure 1. Depicts difference in Operating Time

\begin{tabular}{|c|c|c|c|}
\hline $\begin{array}{c}\text { Post-Operative } \\
\text { Recovery }\end{array}$ & $\begin{array}{c}\text { Prostatectomy } \\
\text { Anatomic } \\
\text { Closure of } \\
\text { Abdomen }\end{array}$ & $\begin{array}{c}\text { Prostatectomy } \\
\text { Mesh Closure of } \\
\text { Abdomen }\end{array}$ & P-value \\
\hline $\begin{array}{c}\text { Duration in } \\
\text { hospital stay } \\
\text { (days) }\end{array}$ & $37.5 \pm 10.61$ & $25 \pm 7.07$ & $<0.01$ \\
\hline $\begin{array}{c}\text { Time taken to } \\
\text { return to normal } \\
\text { work (days) }\end{array}$ & $\begin{array}{c}90 \pm 18.9 \\
(90-120)\end{array}$ & $\begin{array}{c}37 \pm 14.6 \\
(30-45)\end{array}$ & $<0.01$ \\
\hline
\end{tabular}

Table 2. Comparison of Post-Operative Recovery

\section{DISCUSSION}

Of the 30 patients operated and closed with mesh, 18 patients were reported with wound dehiscence, particularly among those with COPD and diabetes. But there was slight discharge from the wound with urine and blood, but the inside of abdomen was not visible and the mesh is seen under covered with peritoneum and behind it the greater omentum, all sufficiently covering the gap in the abdominal wall. Later with daily dressings, blood transfusion and multivitamins and good balanced nutrition, the wounds are healed without necessitating second major operation of abdominal closure in elderly patients with co-morbid conditions. Follow-up continues even today and the outcome is encouraging. None needed second major surgery like abdominal wall closure with tension sutures and later day incisional hernia like in cases of anatomical closure without mesh. It is inevitable to perform open surgery and not TURP, as the tissue that remains after the later procedure can create problems postoperatively pertaining to the actual anatomy of the urinary tract especially the urethra and these aged individuals are on anticlotting medication, though the medicine was stopped few days before surgery. Total removal of the prostate can minimise the chances of later day conversion to prostatic malignancy in some individuals in advanced age groups.

Excessive use of higher antibiotics was avoided to the possible extent, as they may further minimise immunity and enhance the likelihood of severe infections interfering with wound healing. Time to time microbiological culture and sensitivity was done in the selection of suitable antibiotics that work on the cell wall or protein synthesis of the host cells. Certain wound healing factors like vitamin-C, zinc and pyridoxine are given to the patients in injectable form. Postoperative early ambulation is given utmost importance by allotting the physiotherapist.
Also chest physiotherapy prevails all throughout the patient care, both as in-patient as well as for some postoperative period. These simple basic measures do a great lot in the recovery and outcome of the patients.

\section{CONCLUSION}

Routine peroperative closure of abdomen in infraumbilical laparotomy for extraperitoneal transvesical prostatectomy in elderly patients with COPD and diabetes obviates the need for second major surgery and reduces morbidity, enhances recovery[11] and minimises hospital stay. These concluding remarks are very valuable in planning open abdominal surgery in patients with COPD and diabetes also. In anatomic closure patients, the routine outcome is poor with greater morbidity and distressing patient convalescence, whereas in mesh closure cases, a post-operative morbidity is greatly reduced, though even in these cases, some counselling sessions are necessary to improve the morale of the patients. In the absence of COPD, there can be occasional chances of lack of wound dehiscence in certain individuals, though with hypertension but not with diabetes. But in this study, COPD is the main criterion to choose cases for this comparative study with a novel procedure.

\section{REFERENCES}

[1] Williams NS, Bulstrode CJK, O'Connell PR. Bailey \& Love's Short practice of surgery. 26 $6^{\text {th }}$ edn. CRC Press 2013: p. 1340-50.

[2] Van Rij S, Gilling P. Recent advances in treatment for bengin prostatic hyperplasia. [version 1; referees: 2 approved]. F1000Res 2015;4:F1000 Faculty Rev-1482.

[3] Shrivastava A, Gupta AB. Various treatment options for benign prostatic hyperplasia: a current update. Journal of Midlife Health 2012;3(1):10-9.

[4] Varkarakis I, Kyriakakis Z, Delis A, et al. Long-term results of open transvesical prostatectomy from a contemporary series of patients. Urology 2004;64(2):306-10.

[5] Elshal AM, El-Nahas AR, Barakat TS, et al. Transvesical open prostatectomy for bengin prostatic hyperplasia in the era of minimally invasive surgery: perioperative outcomes of a contemporary series. Arab Journal of Urology 2013;11(4):362-8.

[6] Luttwak Z, Lask D, Abarbanel J, et al. Transvesical prostatectomy in elderly patients. J Urol 1997;157(6):2210-1.

[7] Beattie DA. Transvesical prostatectomy. 1950;256(6625):307-8.

[8] Gratzke C, Schlenker B, Seitz M, et al. Complications and early postoperative outcome after open prostatectomy in patients with benign prostatic enlargement: results of a prospective multicenter study. J Urol 2007;177(4):1419-22.

[9] Elnaim ALK, Ibnouf MMM, Toum FM, et al. Post Transvesical Prostatectomy (TVP) complications, risk assessment using Clavien-Dindo System in Kassala Teaching Hospital, Kassala, Sudan. Global Journal of Surgery 2017;5(1):1-5. 
[10] Zaichick V, Zaichick S. Variations in concentration and distribution of several androgen-dependent and independent trace elements in non-hyperplastic prostate gland tissue throughout adulthood. J Androl Gynaecol 2016;4:1-10.
[11] Barrett B, Lewis RW, Terris MK, et al. Designing the rehabilitation of men with post-prostatectomy erectile dysfunction using a pre- and post-operative approach. J Androl Gynaecol 2013;1(1):1-6. 